\title{
Inteligência Emocional: \\ Educação Integral para o Exercício da Cidadania
}

\author{
SILVA, Gisele Reinaldo da ${ }^{1}$ \\ SOUSA, Gabrielle Bloomfield de ${ }^{2}$
}

\section{RESUMO}

Este artigo estuda a Inteligência Emocional como pilar de práticas pedagógicas que fomentem a formação integral de estudantes, para além de conteudismos, de modo a prepará-los para o exercício da cidadania. Partiu-se de uma metodologia qualitativa e bibliográfica, cujo critério de seleção textual pautou-se na relevância temática de artigos, sobretudo, da plataforma SciELO, além de livros de autores especialistas na área. Objetiva-se conceituar Inteligência Emocional, justificar a urgência de sua presença no cenário atual, através da verificação de números de crianças e jovens em idade escolar que têm sido acometidos por diversas doenças psicossomáticas e salientar a necessidade de uma docência que se preocupe em desenvolver competências socioemocionais. Desta forma, a pesquisa contribui para que a escola seja agente de transformação por meio da apropriação da formação socioemocional, de modo a ressignificar seu papel social e proporcionar ação preventiva à incidência de doenças psicossomáticas em jovens e adultos brasileiros.

\section{Inteligência Emocional. Cidadania. Práticas Pedagógicas. Transtornos Mentais Comuns.}

\section{Emotional Intelligence: Integral Education for the citizenship exercise}

\section{ABSTRACT}

This article studies Emotional Intelligence as a pillar of pedagogical practices that promote the integral training of students, beyond content, in order to prepare them for the exercise of citizenship. It was based on a qualitative and bibliographic methodology, whose textual selection criterion was based on the thematic relevance of articles, especially on the SciELO platform, in addition to books by authors specialized in the field. The objective is to conceptualize Emotional Intelligence, justify the urgency of its presence in the current scenario, by verifying the numbers of school-age children and young people who have been affected by various psychosomatic diseases and to emphasize the need of a teaching that is committed with developing socioemotional skills. In this way, the

\footnotetext{
${ }^{1}$ Doutoranda em Ciência da Literatura pela Universidade Federal do Rio de Janeiro. Doutora em Letras Neolatinas pela Universidade Federal do Rio de Janeiro. Mestra em Letras Neolatinas pela Universidade Federal do Rio de Janeiro. E-mail: giselere@gmail.com. Lattes: http://lattes.cnpq.br/1751959433067491. Orcid: https://orcid.org/0000-0002-7524-8890.

2 Pedagoga, professora de educação infantil - Creche Jardim de Sheila. Email: gabbe.bloom@gmail.com. Lattes: http://lattes.cnpq.br/1085888918199034. Orcid: https://orcid.org/0000-0003-4980-0570.
}

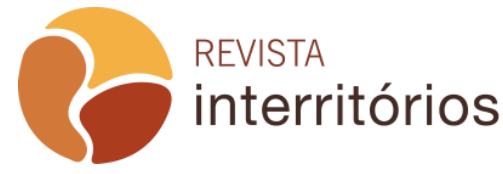


research contributes for the school to be an agent of transformation through the appropriation of socioemotional training, in order to reframe it's social role and provide preventive action to the incidence of psychosomatic diseases in young people and adults in Brazil.

\section{Emotional Intelligence. Citizenship. Pedagogical Practices. Common Mental Disorders.}

\section{Inteligencia Emocional: Educación Integral para el Ejercicio de Ciudadanía}

\section{RESUMEN}

Este artículo estudia la Inteligencia Emocional como un pilar de prácticas pedagógicas que fomentan la formación integral de los estudiantes, más allá del contenido, para prepararlos para el ejercicio de la ciudadanía. Se basó en una metodología cualitativa y bibliográfica, cuyo criterio de selección textual se basó en la relevancia temática de los artículos, especialmente en la plataforma Scielo, además de libros de autores especializados en el área. El objetivo es conceptualizar la Inteligencia Emocional, justificar la urgencia de su presencia en el escenario actual, verificando el número de niños y jóvenes en edad escolar que han sido afectados por diversas enfermedades psicosomáticas y enfatizar la necesidad de enseñar sobre el desarrollo de habilidades socioemocionales. De esta manera, la investigación contribuye a que la escuela sea un agente de transformación a través de la apropiación de la formación socioemocional, con el fin de replantear su papel social y proporcionar medidas preventivas a la incidencia de enfermedades psicosomáticas en jóvenes y adultos brasileños.

\section{Inteligencia Emocional. Ciudadanía. Prácticas Pedagógicas. Trastornos Mentales Comunes.}

\section{Intelligenza emotiva: istruzione integrale per l'esercizio della cittadinanza}

\section{RIASSUNTO}

Questo articolo studia l'intelligenza emotiva come un pilastro delle pratiche pedagogiche che incoraggiano la formazione integrale degli studenti, oltre ai contenuti, al fine di prepararli all'esercizio della cittadinanza. Si basava su una metodologia qualitativa e bibliografica, il cui criterio di selezione testuale era basato sulla pertinenza tematica degli articoli, soprattutto, sulla piattaforma SciELO, oltre ai libri di autori specializzati nel settore. L'obiettivo è concettualizzare l'intelligenza emotiva, giustificare l'urgenza della sua presenza nello scenario attuale, verificando il numero di bambini e giovani in età scolare che sono stati colpiti da varie malattie psicosomatiche e sottolineare la necessità di insegnare che si occupano di sviluppare abilità socioemotional. In questo modo, la ricerca contribuisce a rendere la scuola un agente di trasformazione

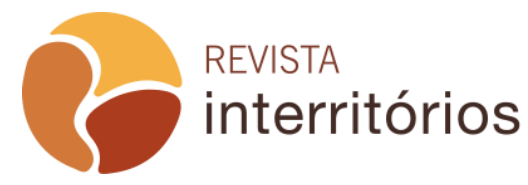


attraverso l'appropriazione della formazione socio-emotiva, al fine di riformulare il suo ruolo sociale e fornire azioni preventive all'incidenza delle malattie psicosomatiche nei giovani e negli adulti in Brasile.

Intelligenza Emotiva. Cittadinanza. Pratiche Pedagogiche. Disturbi Mentali Comuni.

\section{INTRODUÇÃO}

Iniciamos este estudo a partir de um questionamento angular: de que maneira práticas pedagógicas comprometidas com o desenvolvimento de competências socioemocionais podem fomentar a formação integral de educandos em prol do exercício pleno da cidadania? Partimos do entendimento de que o fomento da Inteligência Emocional nas relações de ensino e aprendizagem, para além da tradição escolar conteudista, mas enquanto pilar constitutivo das práticas pedagógicas significativas, será determinante para a formação de educandos aptos ao exercício dos múltiplos papéis demandados pela vida em sociedade. Além disso, compreendemos que as competências socioemocionais não apenas contribuem para a constituição de um ambiente escolar propício à aprendizagem significativa, como também proporcionam ação preventiva à incidência das, cada vez mais incidentes em jovens e adultos brasileiros, doenças psicossomáticas.

Com vistas a aprofundar a discussão acerca do questionamento levantado, propomo-nos, a seguir, a fazer uma revisão bibliográfica qualitativa, pautada nas contribuições propostas em artigos contemporâneos sobre a temática, selecionados, sobretudo, da plataforma SciELO, por sua relevância epistemológica, além das contribuições de especialistas renomados na área da Inteligência Emocional, tais como Daniel Goleman (1996), Augusto Cury (2003), Daniel Chabot e Michel Chabot (2005).

Objetivou-se, neste artigo, apresentar um breve panorama histórico acerca do conceito de Inteligência Emocional; analisar a notoriedade de práticas pedagógicas embasadas no desenvolvimento de competências emocionais, tendo em vista as demandas socioemocionais do atual cenário educacional com enfoque nos transtornos mentais comuns que têm acometido crianças e adolescentes em idade escolar; e, por fim, refletir sobre como a escola pode preparar o educando para lidar com o desempenho dos múltiplos papéis que englobam a vida social, através de práticas pedagógicas intencionais em prol do desenvolvimento da Inteligência Emocional.

\section{Inteligência emocional e transtornos mentais comuns: conceitos e consequências}


Para abordar o histórico da Inteligência Emocional, é preciso, primeiramente, rememorar como pesquisadores chegaram à conceituação da expressão. É preciso destacar os estudos precursores dos psicólogos americanos Edward Lee Thorndike (1920) e Howard Gardner (1995), quando Thorndike (1920) elucida o conceito de "Inteligência Social" como a capacidade de compreender e lidar com as pessoas e Howard Gardner (1995), por sua vez, introduz o conceito de inteligências múltiplas, defendendo que cada pessoa tem um tipo de inteligência dominante, além de criticar a conceituação de inteligência tradicional que considerava apenas aspectos lógico-matemáticos e linguísticos.

No que tange aos avanços no entendimento da Inteligência Emocional, os pesquisadores brasileiros Carla Woyciekoski e Cláudio Simon Hutz (2009) em seu artigo "Inteligência Emocional: Teoria, Pesquisa, Aplicações e Controvérsias", explicam que o entendimento da Inteligência Emocional (IE) como uma habilidade e campo de estudo foi construído através de uma série de artigos publicados nos anos 1990 (MAYER, DIPAOLO, \& SALOVEY, 1990; MAYER \& SALOVEY, 1990), sendo sua precursora uma pesquisa que pensava a conceituação do termo e baseava-se ainda em um modelo de, também, medição de conhecimentos (MAYER, SALOVEY, \& CARUSO, 2002).

A Inteligência Emocional foi, primeiramente, apresentada ao mundo acadêmico por Salovey e Mayer (1990), como uma subcategoria da Inteligência Social, anteriormente proposta por Thorndike, referindo-se à aptidão de perceber as emoções e sentimentos próprios e dos outros, bem como discernir e utilizar essas informações para orientar pensamentos e ações. A partir desses estudos iniciou-se, de 1994 a 1997, a popularização da IE, especialmente, quando o Ph.D americano Daniel Goleman (1996) lançou o livro intitulado Inteligência Emocional: a teoria revolucionária que redefine o que é ser inteligente, o qual, ao democratizar o acesso ao conceito ao público em geral, possibilitou a ampliação e a "mudança" da significação da IE, a qual passou a englobar, também, a preocupação com aspectos da personalidade para aferição das competências socioemocionais.

Em 1992, os psicólogos e pesquisadores britânicos Goldberg e Huxley, por sua vez, criaram o conceito de Transtornos mentais comuns (TMC), os quais dizem respeito ao conjunto de sintomas, de origem multifatorial, não psicóticos, contidos nos diagnósticos de ansiedade, depressão, transtorno de estresse póstraumático, transtorno do pânico, transtorno obsessivo-compulsivo, fobias e estresse, tais como: irritabilidade, fadiga, dificuldade de concentração, esquecimento, insônia e queixas somáticas que denotam situações de abalo mental.

Atualmente, a depressão é reconhecida como questão de saúde pública pela Organização Mundial de Saúde. Segundo seu último boletim informativo, divulgado no segundo semestre de 2017, as estimativas apontam que 322 
milhões de pessoas, em todas as idades, convivem com algum quadro de depressão no mundo e 264 milhões apresentam algum quadro de ansiedade. No Brasil, aponta-se que $5,8 \%$ da população total esteja convivendo com transtornos de depressão e que 9,3\% esteja convivendo com transtornos de ansiedade.

Os Transtornos mentais comuns têm como consequência a diminuição de saúde, pois originam outras doenças psicossomáticas sendo $10,3 \%$ da população brasileira incapacitada em decorrência da depressão e $8,3 \%$ em decorrência da ansiedade, além de esses transtornos constituírem a maior causa de incapacitação de pessoas no mundo. (WORLD HEALTH ORGANIZATION, 2017).

Dentre os possíveis fatores de risco para o desenvolvimento de TMC, podemos destacar os fatores biológicos como: traumatismos cranianos ou outras complicações de nascimento, a exposição a toxinas (ex. tabaco e álcool) na gravidez, etc. Há, ainda, os fatores psicológicos, tais como: transtornos de aprendizagem, traços de personalidade inadaptável, abuso e/ou negligência física, emocional e sexual, temperamento reativo, etc. Além desses, há fatores sociais, tais como: pobreza, morte de pessoas próximas, conflitos familiares, bullying, fracasso escolar, exposição à violência, marginalização e/ou discriminação (de gênero, racial, econômica, etc.), mudanças territoriais, etc. (PATEL et al. 2007)

Tais informações refletem diretamente em como nossos educandos têm chegado às salas de aula. Comumente, completamente desprovidos de habilidades socioemocionais para lidar com as intempéries e demandas do cotidiano e/ou reproduzindo comportamentos nocivos à saúde do ambiente escolar, os quais podem comprometer diretamente o processo de ensino e aprendizagem. Os docentes, por sua vez, encontram-se despreparados para essa mediação emocional, haja vista a falta de formação inicial e continuada adequada na área, bem como a complexidade crescente das adversidades contemporâneas enfrentadas na relação com os discentes.

Daniel Goleman (1996), autor supracitado, já alertava, na década de 90, que as famílias cada vez mais careciam de estrutura para proporcionar uma educação emocional às crianças e jovens e apontava as escolas como agentes de transformação social. Ressalta-se, entretanto, que a necessidade de conscientização da escola com relação à sua incumbência na formação socioemocional dos educandos não anula a parcela de responsabilidade que as famílias, comunidades e demais instituições sociais têm no tocante ao crescimento global dos indivíduos. Nesse sentido, no que tange à escola, é preciso diluir a visão cartesiana de ensino a qual dissocia a mente do corpo, em prol de uma visão integral do sujeito para que, assim, as práticas pedagógicas 
apontem para uma integração entre família e escola em prol do desenvolvimento da inteligência emocional dos discentes.

\section{Competências socioemocionais no currículo básico e o sentir para aprender como evidência neurobiológica}

Apoiada nos marcos legais do artigo 205 da nossa Constituição Federal de 1988 que dispõe os objetivos fundamentais da educação, reiterados pela Lei de Diretrizes e Bases da Educação Nacional 9394/96, a Base Nacional Comum Curricular - BNCC (BRASIL, 2016) entra em vigência como um novo documento de caráter normativo definidor dos conhecimentos essenciais a serem desenvolvidos durante a educação básica pelos estudantes brasileiros em todas as modalidades de ensino, propõe em sua estrutura dez competências gerais de aprendizagem estabelecidas a fim de integrar:

(...) A mobilização de conhecimentos (conceitos e procedimentos), habilidades (práticas, cognitivas e socioemocionais), atitudes e valores para resolver demandas complexas da vida cotidiana, do pleno exercício da cidadania e do mundo do trabalho. Ao definir essas competências, a BNCC reconhece que a educação deve afirmar valores e estimular ações que contribuam para a transformação da sociedade, tornando-a mais humana, socialmente justa e, também, voltada para a preservação da natureza, mostrando-se também alinhada à Agenda 2030 da Organização das Nações Unidas (ONU). É imprescindível destacar que as competências gerais da Educação Básica, apresentadas a seguir, inter-relacionam-se e desdobram-se no tratamento didático proposto para as três etapas da Educação Básica (Educação Infantil, Ensino Fundamental e Ensino Médio), articulando-se na construção de conhecimentos, no desenvolvimento de habilidades e na formação de atitudes e valores, nos termos da LDB. (BRASIL, 2016, p.10).

Essas competências trazem à tona questões pertencentes ao campo da Inteligência Emocional, diretamente, nos seguintes itens:

- Conhecer-se, apreciar-se e cuidar de sua saúde física e emocional, compreendendo-se na diversidade humana e reconhecendo suas emoções e as dos outros, com autocrítica e capacidade para lidar com elas.

- Exercitar a empatia, o diálogo, a resolução de conflitos e a cooperação, fazendo-se respeitar e promovendo o respeito ao outro e aos direitos humanos, com acolhimento e valorização da diversidade de indivíduos e 
de grupos sociais, seus saberes, identidades, culturas e potencialidades, sem preconceitos de qualquer natureza.

- Agir pessoal e coletivamente com autonomia, responsabilidade, flexibilidade, resiliência e determinação, tomando decisões com base em princípios éticos, democráticos, inclusivos, sustentáveis e solidários.

É notório, assim, que os três aspectos acima encontram-se claramente abarcados nos estudos de Peter Salovey e John Mayer (1990), relacionados aos quatro pilares da Inteligência Emocional. São eles: Percepção Emocional, que seria saber ler os nossos sentimentos e emoções, vivenciá-los e classificá-los, como indicativo de uma boa percepção emocional. A Facilitação Emocional, que seria a capacidade de usar as nossas emoções a serviço do nosso pensamento, - que auxiliaria na tomada de decisões mais sábias e no raciocínio mais desenvolto. A Compreensão Emocional, por sua vez, constitui a capacidade de aprender a entender os sentimentos dos outros e os nossos. Já a Regulação Emocional, por fim, consiste na habilidade de controlar nossas reações frente a situações emocionais intensas, sejam elas negativas ou positivas. Uma pessoa equilibrada emocionalmente, nessa conjuntura, saberá escolher qual pensamento prestará atenção evitando deixar-se levar pelos seus primeiros impulsos.

Em todo o seu texto, a BNCC (BRASIL, 2016) defende uma visão de educação em seu caráter integral, considerando que esta deve também assumir um olhar crítico para com a formação socioemocional dos nossos educandos, de forma que só assim consigamos cumprir com o nosso papel de formar cidadãos saudáveis mental e emocionalmente.

Em consonância com o proposto pela legislação acima, trazemos os pesquisadores canadenses Daniel Chabot e Michel Chabot (2005), os quais, em seu livro Pedagogia Emocional: Sentir para aprender, apresentam argumentos neurobiológicos para a implementação de uma educação que enxergue e entenda as emoções. Os autores (2005) alegam que embora a maioria das teorias pedagógicas compreendam que o aprendizado está essencialmente focado no cognitivo, este modelo de aquisição de conhecimentos não dá conta de responder a todos os questionamentos relacionados às dificuldades de aprendizagem.

$\mathrm{Na}$ visão dos autores (2005), parte significativa dos sucessos e dificuldades de aprendizagem pode ser explicada em causas vinculadas ao desenvolvimento de competências emocionais e, para começar a argumentar a favor de sua tese, citam o conceituado Relatório "Compreender o cérebro: Rumo à ciência do novo aprendizado" (2003), da Organização para a Cooperação e o Desenvolvimento Econômico (OCDE), que concorda com a afirmação de que há a necessidade de mais pesquisas na neurociência com relação às atribuições,

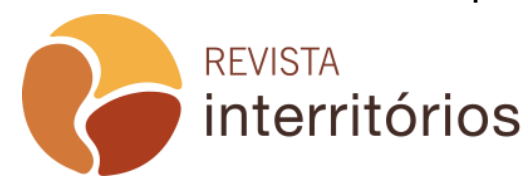

Interritórios | Revista de Educação

Universidade Federal de Pernambuco, Caruaru, BRASIL | V.6 N.11 [2020] 
inegáveis, das competências emocionais no aprendizado de crianças e adolescentes.

De acordo com os Chabot (2005), há a separação clássica entre dois grandes campos de competências: as competências cognitivas (que se relacionam com o saber propriamente dito) e as competências técnicas (que seriam tudo relacionado às habilidades, o saber fazer) e, entre esses dois campos clássicos, há o campo das competências relacionais (que nos propiciam a interação com outras pessoas). Mais adiante, há o campo competências emocionais, as quais propiciam o entendimento sobre não apenas o sentir, mas também o experimentar e reagir conforme as nossas emoções e é notório que o último campo influencia todos os outros.

Tal descoberta sustenta o entendimento dos autores (2015) quanto à notoriedade das competências emocionais de forma que se permite a percepção de que as quatro competências funcionam de forma independente $e$ interdependente, levando à formulação da hipótese de que o âmago do aprendizado não reside nas competências cognitivas, mas nas emocionais.

Com a hipótese anteriormente proposta, os autores (2015) entendem que o aprendizado acontece a depender do sentimento que desenvolvemos em relação à realização da tarefa proposta. Dessa forma, é possível discorrer que inúmeras dificuldades de aprendizagem têm ordem emocional e não cognitiva, como por exemplo, estudantes que são desenvoltos em sua expressividade em momentos de discussão informal, mas quando são solicitados para apresentar seminários ou pequenas apresentações, passam mal e/ou não conseguem desenvolver o raciocínio e as ideias com assertividade e coerência. Há, também, os estudantes que não se expressam ou não são participativos nos momentos de troca simbólica em espaço escolar por uma questão de baixa autoestima ou mesmo por falta do desenvolvimento interpessoal.

Retratos da dita "memória emocional" são grandes motivadores ou desmotivadores da aprendizagem nas escolas. Basta observar como os alunos se referem a disciplinas, conteúdos, professores, situações em sala de aula e buscar o histórico escolar desses mesmos alunos para constatar essa forte relação entre a memória emocional e o desempenho escolar de crianças e adolescentes.

Portanto, ao defenderem que é preciso sentir para aprender, os pesquisadores (2015) propõem uma nova visão de educação e, essencialmente, da prática pedagógica, pautada na perspectiva neurocientífica a qual entende que o processo educativo relacionado ao desenvolvimento de competências cognitivas está intimamente interligado ao avanço das competências socioemocionais, de maneira indissociável, cuja compreensão por parte da comunidade escolar é crucial para o fomento de uma educação de qualidade. 


\section{Alfabetização emocional e outras propostas de educação embasadas na Inteligência Emocional}

A alfabetização emocional prevista pela BNCC (BRASIL, 2016) prevê um entendimento ampliado do que é ser escola, a partir da compreensão de que famílias têm falhado na socialização das crianças, na formação psicológica destas. Essa tarefa demanda duas mudanças fundamentais: a comunidade escolar envolver-se mais com as escolas e os professores atuarem para além da missão tradicional de formação conteudista ou exclusivamente focada no cognitivo. Cabe ressaltar que não há necessidade da criação de uma disciplina específica pra esse conteúdo, de Inteligência Emocional, haja vista que as habilidades socioemocionais devem perpassar as práticas pedagógicas plurais cotidianas, no modo como os conteúdos são abordados e o no modelo de ensino adotado.

Daniel Goleman (1996) assevera, nesta conjuntura, que a capacitação inicial e continuada do professor é uma premissa basilar, visto que a forma como lida com os discentes pode ser por si só reflexo de sua própria competência ou incompetência emocional. Ao estabelecer trocas simbólicas com os alunos, ao lidar com a especificidade de interesses e emoções de cada indivíduo, o docente será desafiado a aprimorar mutuamente as habilidades socioemocionais.

Não obstante, a formação inicial para o magistério, comumente, não engloba esse tipo de preparação, razão pela qual Goleman (1996, p.331) defende a necessidade de alfabetização emocional do docente, visto que "além do treinamento do professor, a alfabetização emocional amplia nossa visão acerca do que é a escola, explicitando-a como um agente da sociedade encarregado de constatar se as crianças estão obtendo os ensinamentos essenciais para a vida".

O currículo escolar aplicado com inserção das competências socioemocionais propiciará que momentos de crise pessoal do indivíduo ao longo da vida sejam transformados em lições de competências emocionais, uma vez que, em sua experiência escolar, através da mediação docente, oportunizouse ao aluno correlacionar as aprendizagens desenvolvidas nesse espaço com as demandas práticas da vida cotidiana.

Outrossim, a aprendizagem socioemocional fomenta o imaginário da escola como espaço onde os educandos se sentem cuidados, respeitados e conectados aos pares, professores e à própria instituição. Os discentes, por sua vez, podem tornar-se multiplicadores destas experiências de aprendizagem significativa, levando à família e comunidade a consciência crítica adquirida no processo de construção de saberes vinculadas às demandas sociais contemporâneas. 
A alfabetização emocional pode começar, por exemplo, com simples rodas de conversa a partir de temas observados no cotidiano escolar pelo docente ou sugeridos pelos alunos os quais engrandeçam as trocas simbólicas, gerem reflexão crítica, autoconhecimento, reconhecimento do lugar do outro, empatia, princípios éticos. Através de diferentes abordagens pedagógicas, como por exemplo debates, uso de vídeos educativos, filmes, séries e jogos educativos, é possível que se construam práticas pedagógicas relevantes à formação plena dos indivíduos.

Neste contexto, Elisa Possebon e Fabrício Possebon (2020), em seu artigo "Descobrir o afeto: Uma proposta de educação emocional na escola", nos trazem o relato de sua pesquisa sobre os impactos de um programa de educação emocional do Núcleo de Educação Emocional da Universidade Federal da Paraíba (Neemoc-UFPB), realizado no município de Queimadas- PB. Por meio deste artigo, percebemos a origem da distinção entre vertentes da Educação Emocional.

Segundo os preceitos de Mayer e Salovey (POSSEBON, POSSEBON, 2020), Inteligência Emocional, no sentido educacional, seria pautada no desenvolvimento das quatro habilidades anteriormente citadas (percepção emocional, facilitação emocional, compreensão emocional e regulação), dispostas em níveis hierárquicos, sendo a regulação reflexiva o nível mais alto de habilidade emocional, como verifica-se no quadro abaixo:

\section{Quadro 1: Representação do modelo de inteligência emocional}

4. Regulação reflexiva das emoções para promover o crescimento emocional e intelectual

4.1 Habilidade para estar aberto aos sentimentos, tanto internos como externos

4.2 Habilidade para atrair ou distanciar-se reflexivamente de uma emoção, dependendo de sua informação ou utilidade

4.3 Habilidade para monitorar reflexivamente as emoções com relação a si mesmo e a outros, tais como reconhecer se são claros, típicos, influentes ou razoáveis

4.4 Habilidade para regular as emoções em si mesmo e nos outros, reduzindo as emoções negativas e intensificando as placentárias, sem reprimir ou exagerar a informação que transmite

3. Compreensão e análise das emoções empregando o conhecimento emocional

3.1 Habilidade para identificar emoções e reconhecer relações entre as palavras e as emoções, tal como a relação entre gostar e amar

3.2 Habilidade para interpretar os significados das emoções e suas relações com seus respectivos estímulos desencadeantes, tal como tristeza e perda

3.3 Habilidade para compreender sentimentos complexos: sentimentos simultâneos de amor e ódio ou mesclados, tais como o temor como uma combinação entre o medo e a surpresa

3.4 Habilidade para reconhecer as transições entre as emoções, tais como a transição da ira à satisfação, ou da ira para a vergonha

\section{Facilitação emocional do pensamento}

2.1 As emoções priorizam o pensamento ao dirigir a atenção à informação importante

2.2 As emoções são tão intensas e disponíveis que podem ser geradas como ajuda ao julgamento e da memória sobre os sentimentos

2.3 O humor modifica a perspectiva do indivíduo desde o otimismo até o pessimismo, favorecendo a consideração dos múltiplos pontos de vista

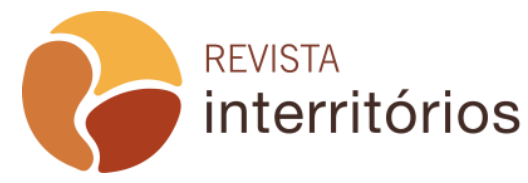

Interritórios | Revista de Educação

Universidade Federal de Pernambuco, Caruaru, BRASIL | V.6 N.11 [2020] 
2.4 Os estados emocionais estimulam o enfrentamento de forma específica cada problema assim como a felicidade facilita o raciocínio indutivo e a criatividade

\section{Percepção, valorização e expressão da emoção}

1.1 Habilidade para identificar a emoção nos estados físicos, sentimentos e pensamentos

1.2 Habilidade para identificar emoções em indivíduos através da linguagem, som, aparência e conduta

1.3 Habilidade para expressar emoções adequadamente e expressar as necessidades relacionadas com esses sentimentos

1.4 Habilidade para discriminar entre expressões de emoções precisas ou imprecisas, honestas ou desonestas

Fonte: (MAYER; SALOVEY,2012, p. 33 apud POSSEBON; POSSEBON 2020, p.167).

Conforme o quadro acima, a vertente da Inteligência Emocional é definida pelos autores como: "um conjunto de disposições comportamentais e de autopercepções acerca das próprias capacidades de identificar, processar e utilizar as informações que possuem elementos de ordem emocional" (POSSEBON E POSSEBON 2020, p. 167).

Já a Competência Emocional (CE), conforme Possebon e Possebon (2020), pautados em Rafael Bisquerra e Núria Escoda (2007), surge como tendência através da crítica de alguns estudiosos ao termo inteligência, pois entende-se competência como uma ação que pode ser aprendida e melhorada com o tempo, e, portanto, mais adequada para o campo educacional. No tocante à sequência didática, a ser trabalhada dentro desta perspectiva de aprender a desenvolver competências emocionais através de situações de fluxo diário, os autores propõem conforme a seguir:

\section{Quadro 2: Representação do modelo de Competência Emocional}

\section{Consciência emocional}

1.1 Consciência das próprias emoções: capacidade de perceber com precisão os sentimentos e emoções da pessoa; identificá-los e rotulá-los.

1.2 Dar nome às próprias emoções: capacidade de usar o vocabulário emocional.

1.3 Compreender as emoções dos outros: capacidade de perceber com precisão as emoções e perspectivas dos outros.

\section{Regulação emocional}

2.1 Tornar-se consciente da interação entre emoção, cognição e comportamento: os estados emocionais afetam o comportamento e as emoções afetam a emoção; ambos podem ser regulados pela cognição (raciocínio, consciência).

2.2 Expressão emocional: capacidade de expressar emoções apropriadamente.

2.3 Capacidade de regulação emocional: os sentimentos e emoções devem ser regulados.

2.4 Competências de enfrentamento: capacidade de lidar com emoções negativas por meio do uso de estratégias de autorregulação que melhorem a intensidade e a duração de tais estados emocionais.

2.5 Competência para emoções positivas autogeradoras: capacidade de experimentar voluntariamente e conscientemente emoções para uma melhor qualidade de vida.

\section{Autonomia pessoal}

3.1 Autoestima: ter uma autoimagem positiva.

3.2 Automotivação: a capacidade de se tornar automotivado e emocionalmente envolvido em várias atividades de lazer pessoal, social, profissional, etc.

3.3 Atitude positiva: capacidade de se auto motivar e ter uma atitude positiva em relação à vida.

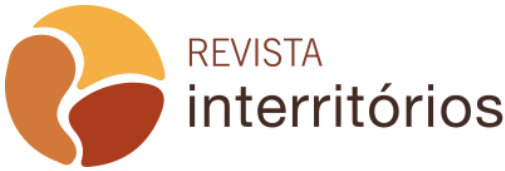


3.4 Responsabilidade: intenção de se envolver em comportamentos seguros, saudáveis e éticos. 3.5 Análise crítica de normas sociais: capacidade de avaliar criticamente as mensagens sociais, culturais e midiáticas relacionadas a normas sociais e comportamentos pessoais.

3.6 Procurar ajuda e recursos: capacidade de identificar a necessidade de apoio e assistência e saber como acessar os recursos disponíveis apropriados.

3.7 Autoeficácia emocional: capacidade de autoeficácia emocional: o indivíduo vê a si mesmo que sente o que quer sentir

4.1 Dominar as habilidades sociais básicas: ouvir, cumprimentar, despedir-se, agradecer, pedir um favor, pedir desculpas, atitude de diálogo, etc.

4.2 Respeito pelos outros: intenção de aceitar e apreciar diferenças individuais e de grupo e valorizar os direitos de todas as pessoas.

4.3 Comunicação receptiva: capacidade de atender aos outros em comunicação verbal e não verbal para receber mensagens com precisão.

4.4 Comunicação expressiva: capacidade de iniciar e manter conversas, expressar claramente seus pensamentos e sentimentos, tanto na comunicação verbal quanto não verbal, e demonstrar aos outros que eles foram bem compreendidos.

4.5 Compartilhar emoções: consciência de que a estrutura e a natureza dos relacionamentos são parcialmente definidas por: a) o grau de imediação emocional ou sinceridade expressiva; e b) o grau de reciprocidade ou simetria no relacionamento.

4.6 Comportamento pró-social e cooperação: capacidade de esperar mudança; compartilhar em situações diádicas e de grupo; manter atitudes de bondade e respeito pelos outros.

4.7 Assertividade: manter um comportamento equilibrado, entre agressividade e passividade; isso implica a capacidade de dizer "não" claramente e mantê-lo, evitar situações em que alguém possa ser pressionado e retardar a atuação em situações de pressão até se sentir adequadamente preparado.

Habilidades de vida e bem-estar solução ou decisão e avaliar riscos, barreiras e recursos.

5.2 Definir objetivos adaptativos: capacidade de definir metas positivas e realistas.

5.3 Solução de conflitos: capacidade de enfrentar conflitos sociais e problemas interpessoais, fornecendo soluções positivas e informadas para os problemas.

5.4 Negociação: capacidade de resolver conflitos em paz, considerando a perspectiva e os sentimentos dos outros.

5.5 Bem-estar subjetivo: capacidade de desfrutar conscientemente o bem-estar subjetivo e procurar transmiti-lo às pessoas com as quais interage.

5.6 Fluxo: Capacidade de gerar experiências ótimas na vida profissional, pessoal e social.

Fonte: (BISQUERRA; ESCODA, 2007, p. 9-12 apud POSSEBON E POSSEBON, 2020, p. 169170).

Haja vista o modelo acima, pode-se entender a abordagem pedagógica com as CEs como uma metodologia que englobe situações corriqueiras no dia a dia, voltando-se para o reconhecimento das sensações que as permeiam. Ou seja, referem-se à realização de alguma tarefa de forma emocionalmente satisfatória, de modo que se mobilizem de forma adequada atitudes, conhecimentos e habilidades.

Conforme este entendimento, define-se Vivência Emocional como:

[..] a possibilidade de instaurar novas aprendizagens de vinculação amorosa e de intensa conexão com a vida e, por isso, estão intimamente relacionadas com a experiência profunda, plena de significado. Além disso, é importante destacar que a dimensão emocional se configura como uma das dimensões humanas, relacionada de forma integrada com as demais. A

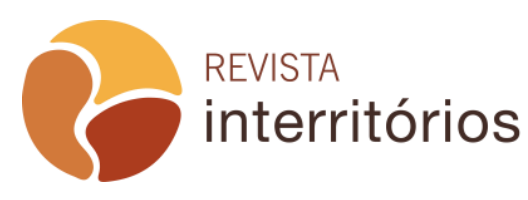

Interritórios | Revista de Educação

Universidade Federal de Pernambuco, Caruaru, BRASIL | V.6 N.11 [2020] 
natureza humana deve ser compreendida em termos mais amplos. (POSSEBON; POSSEBON, 2020, p. 171).

Em outras palavras, no entendimento dos autores (2020), a concepção da Vivência Emocional se trata de um processo educacional que abrange habilidades a serem adquiridas de forma não-linear, pois a capacitação ou 0 treinamento para respostas eficientes não são o que se planeja, mas, sim, o desenvolvimento da pessoa integralmente em que se aprenda sobre aceitação e acolhimento de si e dos outros, expandindo-se até que a consolidação dessas práticas resultem na ascensão de um estado de equilíbrio cada vez maior, como explicitado no quadro abaixo:

\section{Quadro 3: Modelo de representação de Vivência Emocional}

\begin{tabular}{|c|}
\hline Perceber e acolher as emoções sentidas \\
\hline $\begin{array}{l}\text { 1.1 Reconhecer a informação que está associada com a emoção sentida. } \\
\text { 1.2 Verificar se a emoção é a central no processo ou se é uma emoção defensiva, que } \\
\text { obscurece a que é principal. } \\
\text { 1.3 Reconhecer no próprio corpo a emergência emocional. } \\
\text { 1.4 Identificar o estímulo que provoca a emoção. } \\
\text { 1.5 Tomar consciência das próprias emoções, do ponto de vista fisiológico e intersubjetivo. } \\
\text { 1.6 Descrever a emoção com palavras. } \\
\text { 1.7 Dar nome à própria emoção. } \\
\text { 1.8 Identificar se a experiência da emoção está sendo saudável ou desadaptativa. } \\
\text { 1.9 Avaliar se a emoção está sendo vivenciada de forma a proporcionar bem-estar. } \\
\text { 1.10 Reconhecer a qualidade da relação com as outras pessoas mediante o estímulo que } \\
\text { provoca a emoção. } \\
\text { 1.11 Tomar consciência da relação entre emoção, cognição e comportamento. }\end{array}$ \\
\hline Adquirir capacidade de diferenciar e manejar as emoções \\
\hline $\begin{array}{l}\text { 2.1 Representar mentalmente a emoção. } \\
\text { 2.2 Compreender as causas e as consequências da emoção vivenciada. } \\
\text { 2.3 Identificar os pensamentos destrutivos que acompanham o estado emocional. } \\
\text { 2.4 Ressignificar o estímulo. } \\
\text { 2.5 Despertar a própria voz interna qualificadora. } \\
\text { 2.6 Visualizar mentalmente uma situação alternativa, a nova resposta a ser alcançada. } \\
\text { 2.7 Modular a resposta diante do estímulo. } \\
\text { 2.8 Expandir a reação fisiológica vivenciada de forma saudável. } \\
\text { 2.9 Reconhecer e atribuir um significado à emoção. } \\
\text { 2.10 Distinguir a ação a ser implementada. }\end{array}$ \\
\hline Desenvolver a capacidade de refletir de forma crítica e criativa sobre as emoções \\
\hline $\begin{array}{l}\text { 3.1 Reconhecer a necessidade de mudança para proporcionar bem-estar. } \\
\text { 3.2 Identificar situações que requerem uma mudança. } \\
\text { 3.3 Avaliar possíveis dificuldades e obstáculos na consecução da meta. } \\
\text { 3.4 Identificar a meta a ser alcançada. } \\
\text { 3.5 Definir metas positivas e exequíveis. } \\
\text { 3.6 Identificar novos hábitos a serem construídos. } \\
\text { 3.7 Identificar quais as pessoas que podem colaborar neste processo. } \\
\text { 3.8 Auto motivar-se para a realização da meta. } \\
\text { 3.9 Definir objetivos adaptativos. } \\
\text { 3.10 Identificar riscos ou problemas a serem superados. } \\
\text { 3.11 Manter um comportamento assertivo diante da meta a ser alcançada }\end{array}$ \\
\hline $\begin{array}{c}\text { Adquirir capacidade de pensar estrategicamente sobre as emoções } \\
\text { estar }\end{array}$ \\
\hline
\end{tabular}


4.2 Traçar cenários futuros com a nova resposta emocional.

4.3 Dar atenção aos aspectos da situação que podem ser modificados.

4.4 Modificar o foco interno e exercitá-lo.

4.5 Identificar situações que necessitam da estratégia de distração ou de concentração.

4.6 Capacidade de distanciar-se de processos desadaptativos que conduzem à ruminação.

Desenvolver a capacidade de vivenciar as emoções de forma saudável

5.1 Expressar a emoção de forma saudável.

5.2 Lidar com estímulos geradores de ações tóxicas, mediante estratégias de autorregulação.

5.3 Compreender o estado emocional interno e oferecer as melhores respostas.

5.4 Reconhecer os impactos da sua expressão emocional nas outras pessoas.

5.5 Auto motivar-se e envolver-se emocionalmente nas diversas atividades da vida pessoal.

5.6 Desfrutar de bem-estar subjetivo consciente, transmitindo isso nas relações

interpessoais.

5.7 Expressar de forma saudável a emoção.

5.8 Vivenciar a autorregulação emocional.

5.9 Ressignificar os lugares dos estímulos geradores de ações tóxicas.

5.10 Autogerar de forma consciente emoções promotoras de bem-estar.

5.11 Adquirir uma atitude proativa diante da vida.

5.12 Vivenciar o bem-estar

Fonte: (POSSEBON, 2018 apud POSSEBON; POSSEBON, 2020, p. 172-173).

Através deste modelo, os autores (2020) explicam que não se trata, assim, de "treinar" ou "capacitar" pessoas para dar uma resposta eficiente; trata-se de trabalhar o ser integral a partir da harmonização de suas emoções, para que ele possa se colocar diante do outro, reconhecendo e aceitando a si mesmo, acolhendo o outro. A proposta é que, ao longo do tempo, com a regularidade das atividades de educação emocional, os resultados poderão ser obtidos e expressos positivamente mediante a maturação do indivíduo na forma como lida com suas próprias emoções. Abaixo vemos, por fim, um resumo das três vertentes apresentadas de forma sucinta para maior esclarecimento:

\section{Quadro 4: Modelo das Vertentes da Educação Emocional}

\begin{tabular}{|c|c|c|}
\hline $\begin{array}{l}\text { Inteligência Emocional } \\
\text { (IE) }\end{array}$ & $\begin{array}{l}\text { Competência Emocional } \\
\text { (CE) }\end{array}$ & $\begin{array}{c}\text { Vivência Emocional } \\
\text { (VE) }\end{array}$ \\
\hline $\begin{array}{l}\text { - Inteligência e emoção } \\
\text { se distinguem; } \\
\text { - } \quad \text { Atitude ou habilidade } \\
\text { para raciocinar } \\
\text { com a emoção; } \\
\text { - } \quad \text { Destreza para } \\
\text { gerenciar } \\
\text { sentimentos; } \\
\text { - Disposição cognitivo- } \\
\text { comportamental. }\end{array}$ & $\begin{array}{l}\text { - Capacidade ou habilidade } \\
\text { para promover um } \\
\text { resultado positivo; } \\
\text { - Conhecimento das } \\
\text { próprias emoções e } \\
\text { dos demais, para o } \\
\text { desenvolvimento } \\
\text { integral da pessoa; } \\
\text { - Respostas eficazes a } \\
\text { partir do } \\
\text { conhecimento. }\end{array}$ & $\begin{array}{l}\text { - A emoção como } \\
\text { experiência de um } \\
\text { estado da vida; } \\
\text { - A vivência como } \\
\text { possibilidade de } \\
\text { aprendizagem, por ser } \\
\text { uma expressão } \\
\text { original, anterior ao } \\
\text { racional; } \\
\text { - Práticas corporais } \\
\text { integrativas. }\end{array}$ \\
\hline
\end{tabular}

Fonte: POSSEBON E POSSEBON (2020, p. 175).

Através deste quadro, percebe-se a distinção proposta sobre as vertentes para a educação emocional, a qual nos proporciona uma nova visão, inspirada

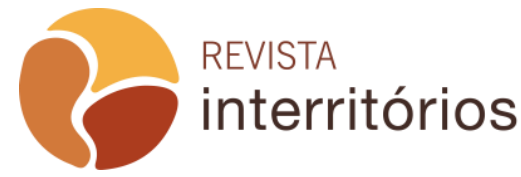


pelos estudos anteriores de Toro (2009), Possebon (2018) e Damásio (2017).

Em consonância com o entendimento supracitado acerca da educação emocional, destacamos as considerações do psicanalista Augusto Cury (2003) a respeito dos sete hábitos de professores fascinantes, os quais desenvolvem práticas pedagógicas contrárias ao estímulo quase exclusivo do cognitivo, mas em suas competências emocionais. São eles:

- Professores fascinantes conhecem o funcionamento da mente:

Bons professores transmitem com segurança os conhecimentos em sala de aula e possuem vasta cultura acadêmica. Porém, professores fascinantes ultrapassam essa competência. Eles buscam compreender o funcionamento da mente dos educandos de forma que não enxerguem seus pupilos apenas como números em sala de aula, mas como seres humanos com suas individualidades. Esses professores destacam-se por transformarem informações em conhecimentos e conhecimentos em experiências, reconhecendo que apenas as experiências são registradas com maestria na memória e são elas, as experiências, que criam possibilidades de transformação da personalidade. Este hábito dos professores fascinantes pode contribuir para que os alunos desenvolvam a capacidade de administrar emoções, gerenciar pensamentos, superar conflitos e trabalhar perdas e frustrações.

- Professores fascinantes possuem sensibilidade:

Bons professores são didáticos, porém, professores fascinantes vão além, possuem sensibilidade para falar com o coração dos seus alunos. Um educador fascinante é o mestre da sensibilidade. Nos pontos de tensão, ele sabe resguardar a emoção. Ou seja, não permite que as atitudes não pensadas dos seus alunos ou a agressividade Ihes tirem a tranquilidade. Ele procura acolher $\mathrm{e}$ compreender mesmo o mais difícil de seus alunos de maneira que não se esquece que além de ser um pilar da escola clássica, é um pilar da escola da vida.

- Professores fascinantes educam a emoção:

Professores fascinantes entendem que educar com a emoção é mais difícil que trabalhar com os mais complexos cálculos algébricos, porém, percebem que muitos suicídios e/ou estados emocionais degradantes podem ser evitados se educandos forem estimulados a pensar antes de reagir, a saber filtrar estímulos estressantes, a não ter medo de sentir medo, a serem autores das suas histórias e a lidar não apenas com problemas concretos mas, sobretudo, com as contradições da vida. Educar a emoção, também, é doar-se sem esperar retorno, é saber tirar prazer do simples da vida, saber perder, correr riscos, ter coragem para andar por lugares desconhecidos e transformar sonhos em realidades. Este hábito dos professores fascinantes colabora para gerar segurança, tolerância, solidariedade, perseverança, proteção contra os estímulos estressantes, Inteligência Emocional e interpessoal.

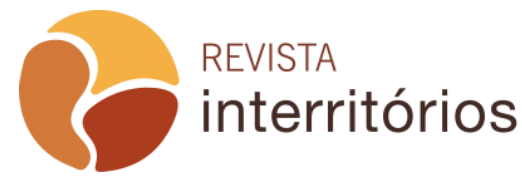

Interritórios | Revista de Educação

Universidade Federal de Pernambuco, Caruaru, BRASIL | V.6 N.11 [2020] 
- Professores fascinantes usam a memória como suporte da arte de pensar:

Ao usar a memória como depósito de informações, é possível tornar-se um bom professor, contudo, professores fascinantes usam a memória como alicerce da inventividade. Bons professores cumprem o conteúdo programático das aulas, professores fascinantes também cumprem o conteúdo programático, no entanto, sua meta essencial constitui ensinar os alunos a serem pensadores críticos e não meros reprodutores de informações. A educação tradicional transformou a memória humana em um banco de dados, não obstante, não é essa sua principal função, mas a de reconstruir de forma criativa o passado.

Os alunos que apresentam desempenho insatisfatório nas avaliações engessadas no agora poderão se tornar excelentes cientistas e profissionais no futuro. Basta que os estimulemos a abrir as portas da mente, a ter ousadia para pensar, romper paradigmas, debater e questionar. Este hábito dos professores fascinantes contribui para desenvolver as seguintes habilidades: pensar antes de reagir, expor e não impor as ideias, a ter consciência crítica, capacidade de debater, de questionar, de trabalhar em equipe.

- Professores fascinantes são mestres inesquecíveis:

Um professor bom é lembrado nos anos de escola. Um professor fascinante é um mestre inesquecível. Um professor bom é admirado, um professor fascinante é amado. Um professor bom se preocupa com o rendimento dos seus educandos, um professor fascinante se preocupa em transformá-los em construtores de ideias. Ser um docente inesquecível é formar seres humanos que intervirão nas mazelas humanas. Suas lições de vida marcam para sempre os conscientes e inconscientes de seus alunos. O professor fascinante inspira as inteligências múltiplas dos educandos, levando-os a enfrentar desafios e não apenas a ter cultura informativa, mas serem estimulados a gerir seus pensamentos de maneira assertiva em cada situação.

Esse hábito de professores fascinantes contribui para desenvolver capacidade de falar ao coração, fomentar sabedoria, afetividade, serenidade, sensibilidade, apreço pela vida, influenciando, assim, de maneira qualitativa nas relações interpessoais.

- Professores fascinantes resolvem conflitos em sala de aula

Diante de qualquer atrito, ofensa ou crise entre os alunos ou dos alunos para com o professor, a melhor resposta é não dar resposta alguma. Cury (2003, p. 48) coloca que: "os primeiros trinta segundos em que estamos tensos, cometemos nossos piores erros, nossas piores atrocidades". Portanto, ao usar a ferramenta do silêncio, o professor pode evitar reações por instinto, as quais podem ser prejudiciais para a construção de um ambiente saudável para os alunos e para ele mesmo. Então, o autor adiciona que o silêncio não será o único responsável pela resolução dos conflitos, há um outro aliado do professor nesses casos: a surpresa. Surpreender os alunos, por exemplo, contando uma história 
ou um caso pessoal da vida do próprio professor pode gerar um grande momento de reflexão não só nos envolvidos no conflito, mas em toda a turma.

Este hábito dos professores fascinantes contribui para desenvolver superação da ansiedade, resolução de crises interpessoais, socialização, proteção emocional, resgate da liderança do eu em focos de tensão.

\section{- Professores fascinantes educam para a vida}

Um bom professor educa seus alunos para uma profissão, um professor fascinante os educa para a vida. Professores fascinantes são profissionais revolucionários. Eles mudam paradigmas, transformam o rumo de um povo e um sistema social. Os mestres fascinantes são incendiários que inflamam a sociedade com o calor da sua inteligência, compaixão e humildade. São fascinantes porque são livres, são livres porque pensam, pensam porque amam a vida. Seus alunos adquirem um bem extraordinário: consciência crítica. Desta forma, não são manipulados, controlados.

Ao contrário, a prática pedagógica desse modelo docente contribui para que os estudantes desenvolverem solidariedade, superação de conflitos psíquicos e sociais, espírito empreendedor, capacidade de perdoar, de filtrar estímulos estressantes, de escolher, de questionar, de estabelecer metas.

\section{Considerações Finais}

Como síntese deste estudo, aludimos à metáfora apresentada por Cury (2003) a qual simboliza a visão global defendida ao longo de todo este estudo, acerca da prática docente contemporânea:

[...] Não podemos nos esquecer que os professores do mundo todo estão adoecendo coletivamente. Os professores são cozinheiros do conhecimento, mas preparam o alimento para uma plateia sem apetite. Qualquer mãe fica um pouco paranoica quando seus filhos não se alimentam. Como exigir saúde dos professores se seus alunos têm anorexia intelectual? É por causa da saúde deles e de seus alunos que a educação tem de ser reconstruída. (CURY, 2003, p. 90).

Tal reflexão proposta por Cury (2003) remete-nos, ainda, à percepção de Rubem Alves (2002), em seu texto "A arte de produzir fome", ao asseverar que o docente necessita, antes de passar por uma escola, passar por uma cozinha a fim de compreender algumas lições, dentre elas, que fome é afeto. $\mathrm{O}$ pensamento nasce do afeto, da fome. Portanto, o docente competente será aquele que, por excelência, seja capaz de produzir tamanha fome de aprendizagem em seus discentes, de modo que os estudantes se sintam estimulados a buscar "saciá-la". 
Em outras palavras, o estímulo às competências socioemocionais em consonância com as habilidades cognitivas devolvem ao aluno o seu lugar de fala, de sentir, de experimentar, de trocar, de saciar-se, de rechaçar, de acolher todas as experimentações protagonizadas por ele nesta fase angular de formação escolar, cujas vivências serão determinantes para sua atuação humana futura, em sociedade, na fase adulta.

\section{REFERÊNCIAS}

ALVES, Rubem. A arte de produzir fome. Folha de São Paulo, vol. 29, n. 10, 2002.

BRASIL. Constituição Federal. Constituição da República Federativa do Brasil. Brasília, DF, 1988. Disponível em:

http://www.planalto.gov.br/ccivil_03/constituicao/constituicao.htm. Acesso em: 15 set 2019.

BRASIL. Lei de Diretrizes e Bases da Educação Nacional. Brasília, DF, 1996.

Disponível em: <http://www. planalto. gov. br/ccivil_03/leis/19394.> Acesso em: 15 set. 2019.

BRASIL. Ministério da Educação. Secretaria da Educação Básica. Base nacional comum curricular. Brasília, DF, 2016. Disponível em:

<http://basenacionalcomum.mec.gov.br/\#/site/inicio\&gt;> Acesso em: 15 set. 2019.

CHABOT, Daniel; CHABOT, Michel. Pedagogia emocional: sentir para aprender. São Paulo, Sá, 2005.

CURY, Augusto. Pais brilhantes, professores fascinantes. Rio de Janeiro, Sextante, 2003.

DAMÁSIO, António. A estranha ordem das coisas: a vida, os sentimentos e as culturas humanas. Lisboa, Círculo de Leitores, 2017.

GARDNER, Howard; VERONESE, Maria Adriana Veríssimo. Inteligências múltiplas: a teoria na prática. 1995.

GOLDBERG, David P.; HUXLEY, Peter. Common mental disorders: a bio-social model. Londres, Routledge, 1992.

GOLEMAN, Daniel. Inteligência Emocional: a teoria revolucionária que redefine o que é ser inteligente. Rio de Janeiro, Objetiva, 1996.

MAYER, John D.; DIPAOLO, Maria; SALOVEY, Peter. Perceiving affective content in ambiguous visual stimuli: A component of emotional intelligence. Journal of personality assessment, v. 54, n. 3-4, p. 772-781, 1990. Disponível em: https://doi.org/10.1080/00223891.1990.9674037. Acesso em: 1 ago. 2019.

MAYER, John D.; DIPAOLO, Maria; SALOVEY, Peter. Emotional intelligence. Imagination, cognition and personality, SAGE Journals, v. 9, n. 3, p. 185-211, 1990. Disponível em: https://journals.sagepub.com/doi/abs/10.2190/DUGG-P24E-52WK6CDG. Acesso em: 20 jul 2019.

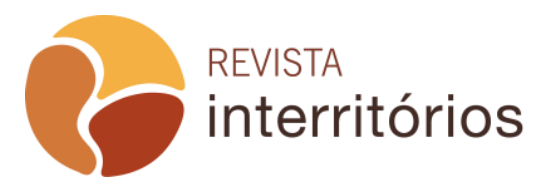

Interritórios | Revista de Educação

Universidade Federal de Pernambuco, Caruaru, BRASIL | V.6 N.11 [2020] 
MAYER John, CARUSO, David. MSCEIT: Mayer-salovey-caruso emotional intelligence test. Toronto, Multi-Health Systems, 2002.

ORGANIZAÇÃO DE COOPERAÇÃO E DESENVOLVIMENTO ECONÔMICOS (OCDE). Compreendendo o cérebro: rumo a uma nova ciência do aprendizado. São Paulo: Senac, 2003.

PATEL, Vikram et al.. Mental health of young people: a global public-health challenge. The Lancet Journal, v. 369, n. 9569, p. 1302-1313, 2007. Disponível em: <https://www.sciencedirect.com/science/article/pii/S0140673607603687 > Acesso em: 01 ago. 2019.

POSSEBON, Elisa Gonsalves. Educação emocional: aplicações. João Pessoa: Libellus Editorial, 2018.

POSSEBON, Elisa Gonsalves; POSSEBON, Fabrício. DESCOBRIR O AFETO: Uma Proposta de Educação Emocional na Escola. Revista Contexto \& Educação, v. 35, n. 110, p. 163-186, 2020. Disponível em:

$<$ https://revistas.unijui.edu.br/index.php/contextoeducacao/article/view/8925> Acesso em: 30 maio 2020.

THORNDIKE, E.L. (1920). Intelligence and its use. Harper's Magazine, 140, 227-235. Disponível em: https://psycnet.apa.org/record/1920-10067-001. Acesso em: 19 Set 2019.

TORO, Rolando. Biodanza. Santiago: Cuarto Próprio, 2009.

WORLD HEALTH ORGANIZATION. Depression and other common mental disorders: global health estimates. Geneva, 2017. Disponível em:

https://apps.who.int/iris/bitstream/handle/10665/254610/WHO-MSD-MER-2017.2eng.pdf. Acesso em: 02 ago 2019.

WOYCIEKOSKI, Carla; HUTZ, Claudio Simon. Inteligência emocional: teoria, pesquisa, medida, aplicações e controvérsias. em Psicologia: reflexão e crítica. Porto Alegre. Vol. 22, n. 1, p. 1-11, 2009. Disponível em:

<https://www.lume.ufrgs.br/handle/10183/30589> Acesso em: 20 set 2019. 